Review Article

\title{
Advanced Analytical and Bioanalytical Estimation of Duloxetine Hydrochloride - An Overview
}

\section{Kranthi Yalla ${ }^{1 *}$, V. Om Vasudev ${ }^{2}$}

1. Assistant professor, Department of Pharmaceutical Analysis, Shri Vishnu College of Pharmacy, Bhimavaram, Andhra Pradesh, India.

2. Department of Pharmaceutical Analysis, Shri Vishnu College of Pharmacy, Bhimavaram, Andhra Pradesh, India.

*Corresponding author's E-mail: Kranthi.y@svcp.edu.in

Received: 06-09-2020; Revised: 24-11-2020; Accepted: 30-11-2020; Published on: 15-12-2020.

\section{ABSTRACT}

Duloxetine $\mathrm{HCl}$ is a drug for the treatment of neuropathic pain associated with peripheral neuropathy especially diabetic polyneuropathy for which it is first line, and as an add-on treatment in stress urinary incontinence instead of surgery also indicated for the management of fibromyalgia. The review describes different procedures for the analysis of Duloxetine HCL as a single drug or in combinations available in the currently available literature in analytical and bioanalytical techniques. The analytical methods described here are explained in Spectroscopic and Chromatographic methods. Advance analytical techniques like HPLC, HPTLC, UFLC, UPLC and LC MS/MS were used to estimate Duloxetine $\mathrm{HCl}$ in pure, dosage forms and in rat/human plasma. This paper certainly helpful for the researchers engaged in method development and validation of Duloxetine $\mathrm{HCl}$.

Keywords: Duloxetine HCl, Bioanalytical, HPTLC, LC MS/MS, RP-HPLC method.

QUICK RESPONSE CODE $\rightarrow$

DOI:

10.47583/ijpsrr.2020.v65i02.024

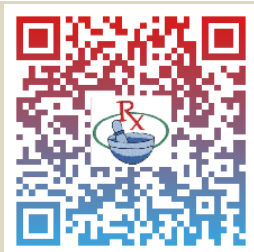

DOI link: $\underline{\text { http://dx.doi.org/10.47583/ijpsrr.2020.v65i02.024 }}$

\section{INTRODUCTION}

uloxetine $\mathrm{HCl}(+)$ - (s)-N-methyl-3-(1napthyloxy)-3(thiophen-2-yl)-propan-1-amine (The Merck Index, 2001) is a potential dual inhibitor of the reuptake of serotonin and norepinephrine (SSNRI). It has been approved by the US Food and Drug administration (USFDA) for the treatment of major depressive disorder and for the diabetic peripheral neuropathic pain. It belongs to the class narcoleptics.

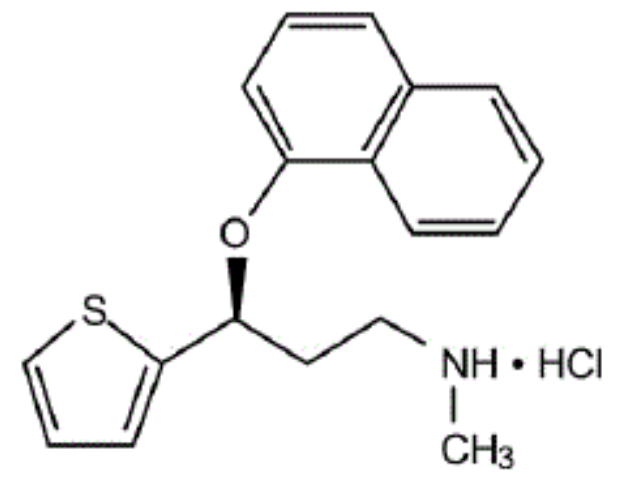

Figure 1: The structure of Dulotoxine Hydrochloride

Molecular formula: $\mathrm{C}_{18} \mathrm{H}_{19} \mathrm{NOS}$.

Molecular weight: $333.9 \mathrm{~g} / \mathrm{mol}$
It is used for the treatment of neuropathic pain associated with peripheral neuropathy especially diabetic polyneuropathy for which it is first line, and as an add-on treatment in stress urinary incontinence instead of surgery also indicated for the management of fibromyalgia. It restores the balance of neurotransmitters in the brain like serotonin and norepinephrine. Additionally, it is also being used in the treatment of peripheral neuropathy caused by certain anticancer drugs ${ }^{1-2}$ According to the guidelines issued by the International Conference on Harmonization (ICH) and European Pharmacopeia it is mandatory to identify and characterize the impurities in a pharmaceutical product if present above the accepted limits of $0.1 \%^{3,4}$. A literature survey revealed different analytical methods for the analysis of Duloxetine hydrochloride API and its key intermediates/process related impurities by HPLC as well as pharmaceutical formulations of Duloxetine hydrochloride ${ }^{5}$. Reports were found regarding the characterization of phenolic impurities in Duloxetine samples by MS, NMR spectrometry and X-ray analysis and of impurities formed by interaction of Duloxetine with various enteric polymers. The aim of the present work is the characterization of Duloxetine hydrochloride and its process related impurities by infrared and nuclear magnetic resonance spectroscopy (IR, NMR), mass spectrometry (MS) / high resolution mass spectrometry (HRMS) and highperformance liquid chromatography. Additionally, Duloxetine hydrochloride polymorph was characterized with X-Ray Powder Diffraction analysis (XRPD), Differential Scanning Calorimetry (DSC), Thermo gravimetric analysis (TGA) and Hot Stage Polarizing Optical Microscopy. Other indications include management of fibromyalgia ${ }^{6}$, generalized anxiety disorder ${ }^{[14]}$ and most recently, stress urinary incontinence ${ }^{7,8}$. Currently, there is no official 
analytical procedure for duloxetine $\mathrm{HCl}$ in any pharmacopoeia.

\section{MATERIALS AND METHODS}

Author searched various online libraries available online, related to determination of Duloxetine Hydrochloride. The databases searched are, pubmed, wiley, sciencedirect, taylor and francis, nature, BMJ and google scholar. The keywords used for search are 'determination of Dulotoxine', 'estimation of Dulotoxine Hydrochloride', and 'Analytical and bioanalytical estimation of Dulotoxine Hydrochloride'.

\section{Analytical methods:}

Thejaswinij.C, et. al., developed the GC-FID method for quantitative determination of duloxetine $\mathrm{HCL}$ in human plasma, where novel chromatographic conditions had been estimated by spiking the plasma with the drug. Elution was carried out on Rtx- 5 capillary with dimensions of $30 \mathrm{~m} \times 0.25 \mathrm{~mm}$ using FID detector. The elution temperature was $60^{\circ} \mathrm{C}$ for $2 \mathrm{~min}$ with $2^{\circ} \mathrm{c}$ per five-minute interval temperature was gradually raised to $85^{\circ} \mathrm{c}$. At $85 \mathrm{Kpa}$ DUL was eluted at retention time of $2.7 \mathrm{~min}$. The linear calibration range was observed between concentrations of 5-50 $\mathrm{mL}^{-1}$. The method developed shown 99.1\% of accuracy, and the inter and intraday precision were $0.234 \%$ and $0.224 \%$ respectively. The LLOD was found to be $0.11 \mu \mathrm{g}$ and LLOQ as $0.34 \mu \mathrm{g}$. A novel GC-FID method was developed for quantitative estimation of DUL in human plasma and validated. The developed method was suitable and economic for routine analysis and pharmacokinetic studies of DUL. ${ }^{9}$

Maha Farouk Abdel-Ghany et. al., developed the StabilityIndicating HPTLC Methods for determination of Milnacipran $\mathrm{HCl}$, Duloxetine $\mathrm{HCl}$, and Pregabalin in both bulk drug and pharmaceutical formulations. The chromatogram was developed on HPTLC using silica gel 60 F254 as precoated plate and the mobile phases used were acetonitrile-water-ammonia $(6+0.6+1.6, v / v / v)$ as $A$, dichloromethane-methanol $(8+1, v / v)$ as $B$, and ethyl acetate-methanol-ammonia $(6+3+0.1, \mathrm{v} / \mathrm{v} / \mathrm{v})$ as C. At wavelengths "220, 230, and $210 \mathrm{~nm}$ " detection was carried out densitometrically. The extraction of drugs in both bulk and pharmaceutical forms were good and utilized chromatographic methods were validated as per international conference on harmonization (ICH) guidelines. The results were compared statistically with reference methods and no significant differences were found. The developed methods were satisfactorily applied to analyse the investigated drugs and proved to be specific and accurate for quality control procedures in pharmaceutical formulations. ${ }^{10}$

Lakshmana Prabu S, et al., developed and validated a new simple, rapid, reproducible and stability indicating HPTLC method for determination of duloxetine hydrochloride in bulk drugs and pharmaceutical formulation. Aluminium precoated 60 GF 254 HPTLC silica gel plates were used for separation. The mobile phases used was chloroform: methanol $(80: 20 \% \mathrm{v} / \mathrm{v})$ with a compact spot at $\mathrm{Rf}$ value of $0.42 \pm 0.1$ and separation of degradation products were also enabled. Densitometric analysis of duloxetine hydrochloride was carried out in the absorbance mode at $216.0 \mathrm{~nm}$. it was found that the correlation coefficient $\left(r^{2}\right)$ was $0.9990 \pm 0.0007$ at a concentration range of $400-2000$ $\mathrm{ng}$ band $^{-1}$ with respect to peak area. The limit of detection and limit of quantitation were found to be 100 and $350 \mathrm{ng}$ band $^{-1}$ respectively. Drug degradation was observed when it is subjected to acid, alkali hydrolysis and oxidation conditions as a part of stability indicating method development. The results of statistical analysis for the estimation of duloxetine hydrochloride proved that the method is repeatable, selective and accurate. ${ }^{11}$

Raja Subburayalu et.al., developed a method for delayed release in pellets of duloxetine hydrochloride using NonIonic barrier layer as an aid. The capsules were evaluated for description, assay, acid resistance and drug release at pH 6.8 phosphate buffer at initial and 6 months accelerated condition $\left(40 \pm 2^{\circ} \mathrm{C} / 75 \pm 5 \% \mathrm{RH}\right)$ so that the required barrier coating to avoid the interaction between duloxetine hydrochloride and enteric polymer can be build up. Among three formulations $10 \%, 15 \%$ and $20 \%$ the former two were failed to control the interaction but $20 \%$ formulation was stable. ${ }^{12}$

Anil Kumar Veeragoni et.al., developed and Validated LCMS bioanalytical method for the Estimation of Duloxetine Hydrochloride in Human Plasma. In this method duloxetine hydrochloride was determined from human plasma and liquid-liquid interaction was considered for estimation of duloxetine hydro chloride. When various parameters were executed as per ICH guidelines using LC-MS the drug in plasma was found to be stable. For the estimation of duloxetine in human plasma this method was found to be sensitive, selective, economic and reproducible. ${ }^{13}$

D. Chandrapal reddy, et.al., developed and validated LC/MS/MS method for determination of duloxetine and its pharmacokinetic study in human plasma. In this method LC-ESI-MS/MS detector and fluoxetine were used as an internal standard. Extraction of analyte and IS from human plasma was done by liquid-liquid extraction using MTBE-n Hexane (80:20). Separation took place on X-terra RP8 (50 $\mathrm{mm}, 4.6 \mathrm{~mm}, 5 \mu \mathrm{m}$ particle size) column by using mixture of $30 \mathrm{mM}$ ammonium formate $(\mathrm{pH}-5.0,0.05)$ and acetonitrile. Elution was isocratic at a flow rate of 0.40 $\mathrm{mL} / \mathrm{min}$ and analyzed by mass spectrometer in the multiple reaction monitoring (MRM) using the respective $\mathrm{m} / \mathrm{z} 298.08 \rightarrow 154.0$ for duloxetine and $310.02 \rightarrow 148.07$ for IS. The linearity was found over a concentration range of $0.100-100.017 \mathrm{ng} / \mathrm{mL}$ in human plasma. The LOD was 0.04 $\mathrm{ng} / \mathrm{mL}$ and the LOQ was $0.100 \mathrm{ng} / \mathrm{mL}$. This method was validated and precision for Intra-batch and Inter-batch was found to be 5.21-7.02. Accuracy for Intra-batch and Interbatch was 97.14103 .50 respectively. Recovery was $80.31 \%$ for duloxetine in human plasma and $81.09 \%$ for ISTD. Pharmacokinetic parameters were AUC0, (1027. 147), C $\max$ 
$(\mathrm{ng} / \mathrm{mL})\left(44.594-0-\mathrm{t},=(984.702-526.502)\right.$ and $\mathrm{T}_{\max }(\mathrm{hr})=$ $(7.25-1.581)^{14}$

K. Bhanu Priya et.al., developed a bioanalytical method development and validation for estimation of duloxetine hydrochloride in human plasma using LC-MS/MS. This method includes usage of LC-MS/MS with electro spray ionization for the quantification of Duloxetine in human plasma. X-Bridge $(4.6 \times 50 \mathrm{~mm}, 3.5 \mu \mathrm{m})$ column was used for Separation of analyte and internal standard using a gradient elution mode were run in positive mode using Telmisartan as IS. Mobile phase was composed of $100 \%$ methanol and $0.1 \%$ formic acid on a reverse phase column and analyzed by MS /MS (API 4000) in the multiple reaction monitoring mode using the respective $\left[\mathrm{M}^{+} \mathrm{H}\right]^{+}$Ions, $\mathrm{m} / \mathrm{z}$ 297.90 to 154.1 for Duloxetine and $\mathrm{m} / \mathrm{z} 515.10$ to 276.30 for IS. A linear dynamic range of 0.5 to $200 \mathrm{ng} / \mathrm{ml}$ for Duloxetine in human plasma was exhibited by the assay. The LOQ was $0.345 \mathrm{ng} / \mathrm{ml}$ with the RSD between $1.19 \%$ to $13.12(n=6)$. Acceptable precision and accuracy were obtained for concentrations over the standard curve range. At room temperature for 4 hours no significant degradation was observed for Duloxetine in human plasma, when subjected to Freeze and thaw cycles. The overall absolute recovery is $73 \%$ to $100 \%$. No matrix suppression was found in the method due to less run time of 1.3 minutes per sample. ${ }^{15}$

P. Srinivasulu, et al., developed a rapid LC-MS/MS method for simultaneous determination of quetiapine and duloxetine in rat plasma and its application to pharmacokinetic interaction study. In this method Eclipse XDB- $\mathrm{C}_{18}$ column was used using acetonitrile and $2 \mathrm{mM}$ ammonium formate containing $0.1 \%$ formic acid mixture. The elution was gradient and eluted within $6.0 \mathrm{~min}$. Quantification was performed in multiple-reactionmonitoring mode with the ion transitions $\mathrm{m} / \mathrm{z}$ $384.4 \rightarrow 253.2$ for quetiapine, $\mathrm{m} / \mathrm{z} 298.1 \rightarrow 154.1$ for duloxetine and $\mathrm{m} / \mathrm{z} 376.2 \rightarrow 165.2$ for IS (haloperidol) respectively. Better linearity at a range of $0.50-100 \mathrm{ng} / \mathrm{mL}$ for quetiapine $\left(r^{2}=0.9972\right)$ and $1.00-200 \mathrm{ng} / \mathrm{mL}$ for duloxetine $\left(r^{2}=0.9982\right)$ was obtained using $50 \mu \mathrm{L}$ of rat plasma, respectively. The method was validated with matrix effects, accuracy, precision, recovery and stability. The validated data was in acceptance criteria according to FDA guidelines. For a pharmacokinetic interaction study this method was applied. The results indicated that under combination use quetiapine had significant effect on the enhanced plasma exposure of duloxetine in rats. This study helps in therapeutic drug monitoring of major depressive disorder patients using such drug combinations. ${ }^{16}$

Pratik Tala et.al., developed an analytical absorption correction method for simultaneous estimation of duloxetine hydrochloride (DULO) and methyl cobalamin (MCA) $n$ their pharmaceutical dosage forms. This method is simple, economical, precise and accurate. The method involves direct estimation of MCA at $351 \mathrm{~nm}$, as at which DULO has zero absorbance at this wavelength with no interference. The corrected absorbance was calculated at
$289 \mathrm{~nm}$ for estimation of DULO, due to the interference of MCA at this wavelength using distilled water as a solvent. At the concentration range of $10-50 \mu \mathrm{g} / \mathrm{mL}$ in both the drugs follow Beer-Lambert's law and this method was statistically validated. ${ }^{17}$

V.R. Sinha, et.al., developed the stress degradation studies on Duloxetine Hydrochloride and also a RP-HPLC method for its determination in Capsule dosage form. The separation was achieved on a C-8 column at a temperature of $40^{\circ} \mathrm{C}$. The mobile phase used was phosphate buffer $(\mathrm{pH}$ 2.5)-methanol-tetrahydrofuran in the ratio of 50:40:10. Flow rate was $1 \mathrm{~mL} / \mathrm{min}$. The detection wavelength was $232 \mathrm{~nm}$. The method was Validated according to $\mathrm{ICH}$ guidelines. The method was linear over a concentration range of $1-100 \mu \mathrm{g} / \mathrm{mL}(\mathrm{n}=6)$. The slope was found to be $85.735 \mathrm{mV} / \mathrm{s} \mathrm{ppm}$ with $\mathrm{r}^{2}$ of 0.9994 and RSD of $0.87 \%$. RSD values ranged from $0.20 \%$ to $0.82 \%$ for intra-day precision studies and $0.63 \%$ to $1.57 \%$ for inter-day precision. The drug stability on exposure of $30 \% \mathrm{H}_{2} \mathrm{O}_{2}$ for $48 \mathrm{~h}$. In acidic conditions it was highly unstable as degradation of $41.35 \%$ was observed in $0.01 \mathrm{~N} \mathrm{HCl}$ at $40^{\circ} \mathrm{C}$ after $8 \mathrm{~h}$. On refluxing the drug for $1 \mathrm{~h}$ degradation was also observed in basic and neutral conditions ( $2.83 \%$ and $42.75 \%$, respectively). ${ }^{19}$

Sevgi Tatar Ulu et,al., developed and validated a method with Pre-Column Derivatization and Fluorescence Detection for determination of Duloxetine Hydrochloride in Capsules by HPLC. The drug was analyzed by HPLC by using an Inertsil C18 column ( $5 \mathrm{~mm}, 15034.6 \mathrm{~mm}$ ). The Mobile phase was composed of methanol and water in the ratio of $65: 35, v / v$. At excitation and emission wavelengths the fluorescence detector was adjusted to 461 and 521 $\mathrm{nm}$, respectively. The linearity was observed in the range of $10-600 \mathrm{ng} / \mathrm{mL}$. LOD and LOQ were 0.51 and $1.53 \mathrm{ng} / \mathrm{mL}$, respectively. ${ }^{20}$

R. Udhaya et.al., developed and proposed the Validation of an UPLC-MS/MS method for simultaneous Quantification of two Selective Serotonin and nor Epinephrine Reuptake Inhibitors and one Selective Serotonin Reuptake Inhibitor in human plasma using setraline as an internal standard. The abovementioned compounds and the internal standard were extracted from $0.5 \mathrm{ml}$ plasma by solid phase extraction method. The separation was carried on a reverse liquid chromatography at $\mathrm{pH}$ 3.9. The elution was in isocratic mode. All analytes were monitored in multiple reaction monitoring mode using the respective $[\mathrm{M}+\mathrm{H}]+$ ions, $\mathrm{m} / \mathrm{z} 2 \mathrm{298.06/153.90}$ for Duloxetine, 279.20/57.75 for Venlafaxine,330.61/162.83 for Paroxetine and $\mathrm{m} / \mathrm{z} 306.14 / 158.71$ for the internal standard. The linearity range for this validated method was found to be $0.5-100 \mathrm{ng} / \mathrm{ml}$ for Duloxetine, Venlafaxine and Paroxetine. The \% RSD of intraday and inter-day assay was in limits. This method was particularly suitable for pharmacokinetic studies for its sensitivity and reliability. ${ }^{21}$

Dantu Durga Rao et.al., developed a method for analysis of Duloxetine Hydrochloride and Its related compounds in pharmaceutical dosage forms and in vitro dissolution studies by stability indicating UPLC. This was a gradient RP- 
UPLC method which was developed for quantitative determination of Duloxetine Hydrochloride in pharmaceutical dosage forms, analysis of related substances and for in vitro dissolution studies. The separation was achieved on a $50 \mathrm{~mm} \times 4.6 \mathrm{~mm}, 1.8 \mu \mathrm{m} \mathrm{C}$ 18 column. Mobile phase A consisted of $67 \%$ of $0.01 \mathrm{M}$ $\mathrm{KH} 2 \mathrm{PO} 4(\mathrm{pH} 4.0)$ buffer, $23 \%$ of tetrahydro furan, and $10 \%$ methanol. Mobile phase B consisted of $60 \%$ of $0.01 \mathrm{M}$ $\mathrm{KH} 2 \mathrm{PO} 4(\mathrm{pH} 4.0)$ buffer and $40 \%$ of acetonitrile. The flow rate was $0.6 \mathrm{~mL} / \mathrm{min}$, and the detection wavelength was $236 \mathrm{~nm}$. The resolution for duloxetine hydrochloride and three potential impurities was found to be 2 . The drug was subjected oxidative, photolytic, hydrolytic and thermal stress conditions. Method is validated as per $\mathrm{ICH}$ guidelines. $^{22}$

N. G. Rashmi et.al., developed and validated method for determination of duloxetine hydrochloride by using RPUFLC method. This bioanalytical method included the estimation of duloxetine hydrochloride drug in human blood plasma: Duloxetine hydrochloride (DLX), an antidepressant drug. Separation of DLX was done on Phenomenex C18 ( $250 \times 4.6,5 \mu \mathrm{m}$ particle size) column by maintaining ambient temperature. Mobile phase consisted of acetonitrile and $0.01 \mathrm{~N}$ potassium dihydrogen orthophosphate in the ratio of 55:45 v/v with an injection volume of $10 \mu \mathrm{l}$ filtered through $0.45 \mu \mathrm{m}$ membrane filter. Flow rate was $1 \mathrm{ml} / \mathrm{min}$ and detection wavelength was $215 \mathrm{~nm}$. Linearity was observed for DLX at a concentration range of $200-1000 \mathrm{ng} / \mathrm{ml}$. The Limit of detection and Limit of quantification for DLX was found to be $100 \mathrm{ng} / \mathrm{ml}$ and $200 \mathrm{ng} / \mathrm{ml}$, respectively. ${ }^{23}$

Renu Chadha et.al., developed and Validated a stability indicating derivative spectrophotometric methods for determination of Duloxetine Hydrochloride. The main objective of the investigation was to develop and validate a simple and reproducible stability indicating derivative spectrophotometric method for the drug in bulk and dosage forms. The method was validated as per $\mathrm{ICH}$ guidelines. Linearity was found at a concentration range of $5 \mu \mathrm{g} / \mathrm{mL}-90 \mu \mathrm{g} / \mathrm{mL}$ with $\mathrm{r}^{2}$ of 0.999 . LOD and LOQ were found in the range from $0.33-0.41 \mu \mathrm{g} / \mathrm{mL}$ and $1.01-1.24$ $\mu \mathrm{g} / \mathrm{m}$, respectively. This method was applicable for the determination of the drug in capsules and the \% recovery was found to be $99.68 \pm 0.95 \%{ }^{24}$

Mohammad yunoos, et.al., developed a simple UV Spectrophotometric method for the determination of Duloxetine Hydrochloride in bulk and in pharmaceutical dosage forms. The method was simple and sensitive. Duloxetine hydrochloride shows absorption maxima at 288 $\mathrm{nm}$ with apparent molar absorptivity of $0.97 \times 104 \mathrm{~L} / \mathrm{mol} . \mathrm{cm}$ in $0.1 \mathrm{~N} \mathrm{HCL}$. In the concentration range of $5-30 \mu \mathrm{g} / \mathrm{mL}$ Beer's law was found to be obeyed. This method was accurate, precise and economical. This method was successfully applied for the analysis of the drug in bulk and in its capsule dosage forms. ${ }^{25}$

\section{CONCLUSION}

The methods discussed above were mostly HPLC and LC MS/MS for estimation of Duloxetine hydrochloride. HPLC and LC MS/MS were used for the estimation of drug in biological fluids. One GC-FID method was discussed for estimation of drug in human plasma on capillary with temperature control. Some methods were developed by using HPTLC for estimation of Duloxetine hydrochloride and for its stability studies. An absorption correction method was also developed for Duloxetine hydrochloride in combination and corrected its absorbance to $289 \mathrm{~nm}$.A Simple UV Spectrophotometric method was developed for the determination of Duloxetine Hydrochloride in Bulk and in Pharmaceutical Formulations. In above all discussed methods it is found that LC MS/MS serves better method for estimation of Duloxetine Hydrochloride in human and rat plasma.

\section{ABBREVIATIONS}

- HPLC - High performance liquid chromatography

- RP-HPLC - Reverse phase High performance Liquid chromatography

- UPLC - Ultra Performance Liquid chromatography

- MS - Mass Spectrometry

- LC - Liquid chromatography

- MS/MS - Tandem mass spectrometry

- UV - Ultra violet spectroscopy

\section{REFERENCES}

1. Freeman MP, Hirschberg AM, Wang B, Petrillo LF, Connors S, Regan S, Joffe H, Cohen LS “Duloxetine for major depressive disorder and daytime and night time hot flashes associated with the menopausal transition", 'Maturitas', 75 (2), 2013, 170-174.

2. Patel SK, Patel BH, "Estimation of duloxetine Hydrochloride in pharmaceutical formulations by RP-HPLC method", 'Ind J Pharm Sci', 70(6), 2010, 825-827.

3. Raman VVSSN, Harikrishna AK, Ratnakar RK, Prasad VVSSA, Ramakrishna K. "Determination of duloxetine hydrochloride in the presence of process and degradation impurities by a validated stability-indicating RP-LC method", 'J Pharm Biomed Anal', 51(4), 2010, 994-997.

4. Bhimanadhuni CN, Garikapati DR, Srinivas C., "Development and validation of RPHPLC method for determination of Duloxetine hydrochloride in bulk and dosage form", 'Int Curr Pharm J', 1(5), 2012, 98-102.

5. Puranik M, Wadher S, Sharma K. "A Simple, novel validated stability indicating RPHPLC method for estimation of duloxetine $\mathrm{HCl}$ in capsule pharmaceutical formulation", "Ind J Pharm Edu Res', 48, 2014, 91-98.

6. National Institute for Health and Clinical Excellence, Urinary incontinence the management of urinary incontinence in women, (2006) NW, London. 
7. Wolfe F, Smythe HA, Yunus MB, Bennett RM, Bombardier C., Goldenberg DL, Tugwell P., Campbell SM, Abeles M., Clark P., "Criteria for the classification of fibromyalgia", 'Arthritis Rheum' 33, 1990, 16-72.

8. Douglas RD., "Treating Patients for Comorbid Depression, Anxiety Disorders and Somatic illnesses", 'J. Am. Osteopath Assoc.', 106, 2006, s1-S8.

9. Thejaswini J. C., Gurupadayya B. M. and Ranjith kumar K., "Quantitative determination of duloxetine $\mathrm{HCL}$ in human plasma by GC-FID method". "international journal of pharmacy and pharmaceutical sciences, VOL5, 2013,405408.

10. Maha Farouk Abdel-Ghany, Omar Abdel-Aziz and Eman Wafik Eskander., "Stability-Indicating HPTLC Methods for Determination of Milnacipran $\mathrm{HCl}$, Duloxetine $\mathrm{HCl}$, and Pregabalin in Bulk Drug and Pharmaceutical Formulations", 'Analytical chemistry: An Indian journal' vol 17, 2017, 246267.

11. Lakshmana Prabu S, Suriyaprakash T.N.K. and Thiyagarajan S., "Development and validation of stability indicating high performance thin layer chromatography assay method for estimation of duloxetine hydrochloride in bulk drug and pharmaceutical dosage form, Elixir International Journal. 35, 2011, 2816-2819.

12. Raja Subburayalu, Dr. Janaki Raman Kunchithapatham, Dr. Ramkumar Pillappan, "Formulation and Stabilization of Duloxetine Hydrochloride Delayed Release Pellets with the Aid Non-Ionic Barrier Layer", 'IOSR Journal of Pharmacy', 3,2013,63-70.

13. Anil Kumar Veeragoni, Vasudeva Murthy Sindgi and Shoba Rani Satla., "Validated LC- MS Bioanalytical Method for the Estimation of Duloxetine Hydrochloride in Human Plasma.", 'Scholars Research Library, Der Pharmacia Lettre', 8(8), 2016,355-360.

14. D. Chandrapal reddy, A. T. Bapuji, V. Suryanarayana rao, V. Himabindu, D. Rama raju1, Syed Syedba and H. L. V. Ravikirani., "Development and Validation of a LC/MS/MS Method for the Determination of Duloxetine in Human Plasma and its Application to Pharmacokinetic Study", 'CODEN ECJHAO E-Journal of Chemistry', 9(2), 2012, 899911.

15. K. Bhanupriya, Savithri shivakumar, A. Ravi, K.V. Ramanjaneyulu, P. Venkateswara Rao, A.M.S. Sudhakar babu., "Bioanalytical method development and validation for estimation of duloxetine hydrochloride in human plasma using Ic-ms/ms.", 'Asian Journal of Pharmaceutical Analysis and Medicinal Chemistry', 4(1), 2013, 18- 38.

16. P. Srinivasulu, K. S. V. Srinivas, R. S. Reddy, K. Mukkanti, R. Buchireddy., "A validated stability indicating rapid LC method for duloxetine $\mathrm{HCl}$., Department of Analytical
Research and Development”, 'Pharmazie' 64, 2009,10-13, doi: $10.1691 /$ ph.2008.8157.

17. Pratik Tala, Bipin Paghadar, Komal Dhudashia, Trusha Bhaliya, Ankit Nariya., "Analytical method development and validation for simultaneous estimation of duloxetine hydrochloride and methyl cobalamin in their pharmaceutical dosage form by absorption correction method", 'International Journal of Research in Pharmaceutical and Nano Sciences', 2(2), 2013, 213 - 220.

18. N.V. Satheesh Madhav, Deepika Raina., "Formulation and evaluation of Duloxetine loaded bio-nano suspension for brain specificity via acoustic meatus", 'SOJ Pharmacy \&amp; Pharmaceutical Sciences', SOJ phrm sci (4)1, 2016, 1-5.

19. V.R. Sinha, Anamika, R. Kumria, and J.R. Bhinge., "Stress Degradation Studies on Duloxetine Hydrochloride and Development of an RP-HPLC Method for its Determination in Capsule Formulation", 'Journal of Chromatographic Science', Vol. 47, August 2009,2816-2819.

20. Sevgi Tatar Ulu., "Determination and Validation of Duloxetine Hydrochloride in Capsules by HPLC with PreColumn Derivatization and Fluorescence Detection", 'Journal of Chromatographic Science' 50,2012, 494-498 doi:10.1093/chromsci/bms034 Advance Access publication April 17, 2012.

21. Amandeep Singh and Alka Bali., "Formulation and characterization of transdermal patches for controlled delivery of duloxetine hydrochloride", 'Journal of Analytical Science and Technology', 7 (2016), 7-25. DOI 10.1186/s40543-016-0105-6.

22. R. Udhaya, Petla. Y. Naidu, A. Rajasehkara Reddy, T. V. Vidya Sagar., "Validation of an UPLC-MS/MS method for simultaneous Quantification of two Selective Serotonin and nor Epinephrine Reuptake Inhibitors and one Selective Serotonin Reuptake Inhibitor in human plasma", 'Scholars Research Library, Der Pharma Chemica', 4 (3), 2012, 11641173., ISSN 0975-413X.

23. N. G. Rashmi, Hanumanthachar Joshi and B. M. Gurupadayya., "Bio-analytical method development and validation for the determination of duloxetine hydrochloride by using RP-UFLC method", 'European Journal of Biomedical AND Pharmaceutical sciences', ejbps, Volume 4, 2017, 464469.

24. Renu Chadha and Alka Bali., "Development and Validation of Stability Indicating Derivative Spectrophotometric Methods for Determination of Duloxetine Hydrochloride", 'British Journal of Pharmaceutical Research' 6(6), 2015, 402-414, Article no. BJPR.2015.082 ISSN: 2231-2919.

25. Mohammad yunoos, et al., "Simple UV Spectrophotometric Determination of Duloxetine Hydrochloride in Bulk and in Pharmaceutical Formulation", 'E Journal of Chemistry', 7(3), 2010, 785-788., ISSN: 0973-4945.

Source of Support: None declared.

Conflict of Interest: None declared.

For any question relates to this article, please reach us at: editor@globalresearchonline.net

New manuscripts for publication can be submitted at: submit@globalresearchonline.net and submit_ijpsrr@rediffmail.com 